\title{
ADS-5102 (Amantadine) Extended-Release Capsules for Levodopa-Induced Dyskinesia in Parkinson's Disease (EASE LID 2 Study): Interim Results of an Open-Label Safety Study
}

\author{
Robert A. Hauser ${ }^{\mathrm{a}, *}$, Rajesh Pahwa ${ }^{\mathrm{b}}$, Caroline M. Tanner ${ }^{\mathrm{c}}$, Wolfgang Oertel $^{\mathrm{d}}$, Stuart H. Isaacson $^{\mathrm{e}}$, \\ Reed Johnson ${ }^{\mathrm{f}}$, Larissa Felt ${ }^{\mathrm{f}}$ and Mary Jean Stempien ${ }^{\mathrm{f}}$ \\ ${ }^{a}$ University of South Florida, Tampa, FL, USA \\ ${ }^{\mathrm{b}}$ University of Kansas Medical Center, Kansas City, KS, USA \\ ${ }^{\mathrm{c}}$ University of California San Francisco and San Francisco Veterans Affairs Medical Center, San Francisco, \\ CA, USA \\ ${ }^{\mathrm{d}}$ Philipps University, Marburg, Germany \\ e Parkinson's Disease and Movement Disorders Center of Boca Raton, Boca Raton, FL, USA \\ ${ }_{\mathrm{f}}^{\mathrm{f}}$ Adamas Pharmaceuticals, Inc., Emeryville, CA, USA
}

\begin{abstract}
.
Background: Medical treatment of levodopa-induced dyskinesia (LID) in Parkinson's disease (PD) is an unmet need. ADS-5102 (amantadine) extended-release capsules is being developed for the treatment of LID in patients with PD.

Objective: Evaluate the long-term safety and tolerability of $274 \mathrm{mg}$ ADS-5102 for LID in PD.

Methods: In an ongoing, open-label safety study (NCT02202551), PD patients with LID received $274 \mathrm{mg}$ of ADS-5102 once daily at bedtime. Patients were recruited from previous ADS-5102 trials. In addition, patients were enrolled who were ineligible for previous ADS-5102 trials due to previous implantation of deep-brain stimulation (DBS) devices. The primary outcome measure was safety assessed through adverse events (AEs). Efficacy was assessed using the Movement Disorder Society-Unified Parkinson's Disease Rating Scale (MDS-UPDRS), Part IV and its subparts.

Results: For this interim analysis, 223 patients received ADS-5102 for a mean duration of 348 (SD 182) days. The most common AEs included falls (25.1\%), visual hallucinations (19.3\%), peripheral edema (13.0\%), and constipation (12.6\%). Overall, 32 patients (14.3\%) discontinued due to an AE. In patients receiving placebo in previous studies, the mean MDSUPDRS, Part IV scores decreased by 3.4 points from baseline $(n=78)$ to week 8 and remained stable through week 64 $(n=21)$. In patients receiving ADS-5102 in previous studies, the mean baseline $(n=61)$ MDS-UPDRS, Part IV score was low due to the response to ADS-5102 in previous studies and remained stable through week 64 (total of 88 weeks; $n=21$ ). The effect was primarily due to reduction in item 4.2 (functional impact of dyskinesia) and item 4.4 (functional impact of motor fluctuations).
\end{abstract}

\footnotetext{
*Correspondence to: Robert A. Hauser, MD, USF Parkinson's Disease and Movement Disorders Center, National Parkinson Foundation Center of Excellence, USF Health - Byrd Institute,
}

4001 E. Fletcher Ave, 6th Floor, Tampa, FL 33613, USA. Tel.: +1 813396 0765; Fax: +1 813905 9829; E-mail: rhauser@health.usf.edu. 
Conclusions: ADS-5102 was generally well tolerated in all groups, including DBS patients, and the safety profile was consistent with previous controlled studies. Long-term durability and tolerability were shown from the double-blind studies through participation in the open-label study up to 88 weeks.

Keywords: Parkinson's disease, levodopa-induced dyskinesia, dyskinesia, amantadine

\section{INTRODUCTION}

Parkinson's disease (PD) is a progressive neurodegenerative disorder affecting almost one million people in the US [1]. PD is characterized by the progressive loss of dopaminergic neurons resulting in reduced endogenous striatal dopamine, leading to cardinal symptoms of bradykinesia, rigidity, tremor, and postural instability [2]. Levodopa, a dopamine precursor, is considered the most effective treatment option for PD motor symptoms [3].

In $\mathrm{PD}$, with the progressive loss of dopaminergic neurons, the temporal effect of levodopa is reduced over time and levodopa's therapeutic effect ultimately matches its pharmacokinetic profile. This causes local fluctuations in dopamine levels, which results in overactivated NMDA receptor signaling, a potential cause of levodopa-induced dyskinesias (LID) and motor fluctuations (OFF time). As the continuous effects of levodopa are lost, motor fluctuations begin to complicate PD management. End-of-dose "wearing off" (return of PD symptoms before the next dose of levodopa takes effect) and dyskinesias (involuntary movements during waking hours that are nonrhythmic, purposeless, and unpredictable) begin to arise and may severely impact health-related quality of life $[4,5]$.

LID are reported by $\sim 40 \%$ of patients after 4 to 6 years of levodopa therapy and nearly all (90\%) after 10 years [6]. LID are associated with a variety of morbidities including impaired activities of daily living, decreased health-related quality of life, and falls. LID are also associated with increased healthcare utilization and increased caregiver burden [7-10]. However, there is no FDA-approved medical treatment for LID.

Amantadine is an uncompetitive NMDA receptor antagonist. Amantadine $\mathrm{HCl}$ immediate release (amantadine IR) was originally approved for influenza with an additional indication of parkinsonism. It is also sometimes used off-label to treat LID in patients with PD. There are a number of small studies that suggest amantadine IR reduces dyskinesia; however, the drug has not been extensively studied in well-controlled clinical trials, and durability of its effect has been questioned. Despite the same body of trial evidence, there are differing recommendations across various guidelines [11, 12]. While $200 \mathrm{mg}$ daily of amantadine $\mathrm{HCl}$ IR (equivalent to $162 \mathrm{mg}$ amantadine) can be well tolerated, higher doses may be more efficacious but associated with a greater incidence of central nervous system (CNS) side effects, especially hallucinations, edema, and sleep disruption $[13,14]$.

ADS-5102 (amantadine) extended-release capsules, administered once daily at bedtime, is in development for the treatment of LID. In three double-blind, placebo-controlled efficacy studies, ADS-5102 (274 mg amantadine, equivalent to $340 \mathrm{mg}$ amantadine $\mathrm{HCl}$ ) once daily at bedtime significantly reduced LID with a secondary benefit of reduction in OFF time [15-17].

ADS-5102 was designed to deliver a distinct concentration-time profile of amantadine that is not achievable with amantadine IR. With ADS-5102, the initial slow rise in plasma concentration overnight achieves twice the amantadine plasma level as amantadine IR during the early morning and daytime ( $\sim 1000-1500 \mathrm{ng} / \mathrm{mL}$ ), when symptoms can be most bothersome [18]. The once-daily dosing regimen may also provide enhanced convenience and improve compliance, compared with multiple dosing of amantadine IR.

We report interim results of an ongoing openlabel trial to evaluate long-term safety and efficacy of ADS-5102 for treatment of LID.

\section{MATERIALS AND METHODS}

\section{Study design and patients}

Between July 28, 2014, and March 10, 2016, patients were screened and evaluated for eligibility for an open-label trial of ADS-5102 for the treatment of LID in patients with PD. An interim analysis was performed with a data cut-off date of December 2, 2016, to evaluate the safety and tolerability of ADS5102. The study protocol and patient consent forms were approved by each site's institutional review board, research ethics board, or an independent ethics 
committee. All patients provided written informed consent prior to any study procedures.

Patients were recruited after completing participation in an ADS-5102 double-blind trial. Patients who were ineligible for an ADS-5102 trial because they had undergone a deep-brain stimulation (DBS) procedure were also recruited to this safety trial. The study population is summarized for all study participants as well as 3 subgroups based on their prior study participation or prior DBS:

- Patients receiving ADS-5102 in the EASE LID [15] or EASE LID 3 trial [17] who enrolled in the extension without a time gap (previous active group)

- Patients receiving placebo in the EASE LID [15] or EASE LID 3 trial [17] who enrolled in the extension without a time gap (previous placebo group)

- Patients who were otherwise eligible but excluded from prior trials because they had been treated with DBS (prior DBS group)

Twenty-two subjects were also enrolled after time gaps following their participation in a double-blind study (EASED [16], EASE LID [15], or EASE LID 3 [17]). These subjects are not summarized as a subgroup due to the small number of subjects, but are included in the analysis of all study participants.

Eligibility criteria for all patients were the following: diagnosed with PD per the UK Parkinson's Disease Society Brain Bank, receiving levodopa preparation concomitantly, current history of peakdose dyskinesia that the patient and investigator felt might benefit from specific dyskinesia treatment or receiving treatment with amantadine. Other key inclusion criteria required patients to be ambulatory with or without aids (e.g., walker or cane while ON) and to be taking a stable regimen of antiparkinson medications that included a levodopa preparation administered $\geq 3$ times daily for $\geq 30$ days prior to Screening and throughout the study. If the patient needed a partner to assist with study assessments, that person was to be knowledgeable and able to accompany the patient to study visits. Key exclusion criteria included withdrawal from a previous controlled study due to an ADS-5102-related AE, orthostatic hypotension at Screening, a major psychiatric disorder, renal impairment (estimated glomerular filtration rate (eGFR) $<50 \mathrm{~mL} / \mathrm{min} / 1.73 \mathrm{~m}^{2}$ ) and current or anticipated need for treatment with a restricted medication per protocol.
Enrolled patients were treated for up to 101 weeks with a daily ADS-5102 dose of $137 \mathrm{mg}$ (1 capsule) during the first week of treatment, $274 \mathrm{mg}$ (2 capsules) during Weeks 2 through 100, and $137 \mathrm{mg}$ (1 capsule) during the last week of treatment (Week 101). Study drug was taken once daily at bedtime.

\section{Outcomes}

Safety was assessed through AE reporting (including serious AEs [SAEs]), physical examinations, vital signs, and laboratory parameters. Efficacy was assessed through the Movement Disorder Society-Unified Parkinson's Disease Rating Scale (MDS-UPDRS), Part IV (motor complications) and its subparts.

Hematology, serum chemistry, and urinalysis tests were performed at Screening and all follow-up visits except the Safety Follow-up Visit (Week 103); these were Weeks 4, 8, 16, 28, 40, 52, 64, 76, 88, and 100 (or Early Termination). A complete physical examination was performed at Screening, Weeks 16, 52, and 100 (or Early Termination), and a targeted physical examination was performed on Day 1 (Baseline), Weeks 4, 8, 28, 40, 64, 76, 88, and during the Safety Follow-up Visit. Evaluation of patients for orthostatic hypotension was performed at Screening, and vital signs were measured at all follow-up visits.

During the study, the investigator was responsible for reporting all directly observed and spontaneously reported AEs, including SAEs. The severity (mild, moderate, or severe) and study-drug relationship (related or not related) of the $\mathrm{AE}$ was classified according to the investigator's clinical judgment. Adverse events were coded according to the Medical Dictionary for Regulatory Activities (MedDRA) version 17.0.

For this study, changes in LID-related signs or symptoms were captured on the MDS-UPDRS as efficacy outcomes and were not considered as AEs. The MDS-UPDRS rating was performed at Screening and Weeks 8, 16, 28, 40, 52, 64, 76, 88, and 100 (or Early Termination).

\section{Statistical analyses}

All patients who received at least one dose of study drug were included in the safety analysis. All patients who received at least one dose of study drug and provided at least one post-baseline MDSUPDRS assessment were included in the efficacy analysis. Four analysis groups were defined based 
on the patients' prior study experience or prior DBS.

- Previous active group

- Previous placebo group

- Prior DBS group

- All patients included in the study

Data were summarized by analysis group and overall using descriptive statistics.

\section{RESULTS}

\section{Patients}

Between July 28, 2014, and March 10, 2016, 243 patients were screened and 223 patients were enrolled (Fig. 1). Enrollment is completed, the study remains ongoing, and future data cuts are expected to support a New Drug Application (NDA) submission. All enrolled patients received at least 1 dose of ADS5102; 2 patients withdrew from the study before the first post-baseline efficacy assessment and were excluded from all efficacy analyses. At the cut-off date (December 2, 2016) 147 patients were participating in the ongoing study, 13 patients had completed the study, and 63 patients had discontinued the study drug and withdrawn for various reasons (Fig. 1). The
Table 1

Study drug duration of exposure

\begin{tabular}{lc}
\hline & $\begin{array}{c}\text { Safety Population } \\
(\mathrm{N}=223)\end{array}$ \\
\hline Study drug duration of exposure, days & \\
Mean & 347.7 \\
SD & 182.1 \\
Median & 363.0 \\
Min, Max & 2,721 \\
No. (\%) of patients remaining in study at: & \\
Week 4 & $215(96.4)$ \\
Week 8 & $206(92.4)$ \\
Week 16 & $194(87.0)$ \\
Week 28 & $183(82.1)$ \\
Week 40 & $168(75.3)$ \\
Week 52 & $120(53.8)$ \\
Week 64 & $72(32.3)$ \\
Week 76 & $52(23.3)$ \\
Week 88 & $33(14.8)$ \\
Week 100 & $14(6.3)$ \\
\hline
\end{tabular}

mean duration of ADS-5102 exposure was 348 days overall (Table 1).

The mean patient age was 63.7 (SD 9.3) years at baseline and the majority of patients were male (58.7\%) and white (93.3\%). The mean duration of PD was 11.8 (SD 5.3) years, mean duration of levodopa treatment was 9.3 (SD 4.7) years, and mean duration of LID was 5.3 (SD 3.7) years (Table 2). Dopamine agonists were used by $60.1 \%$ and monoamine oxidase inhibitors by $43.5 \%$. Various other antiparkinson

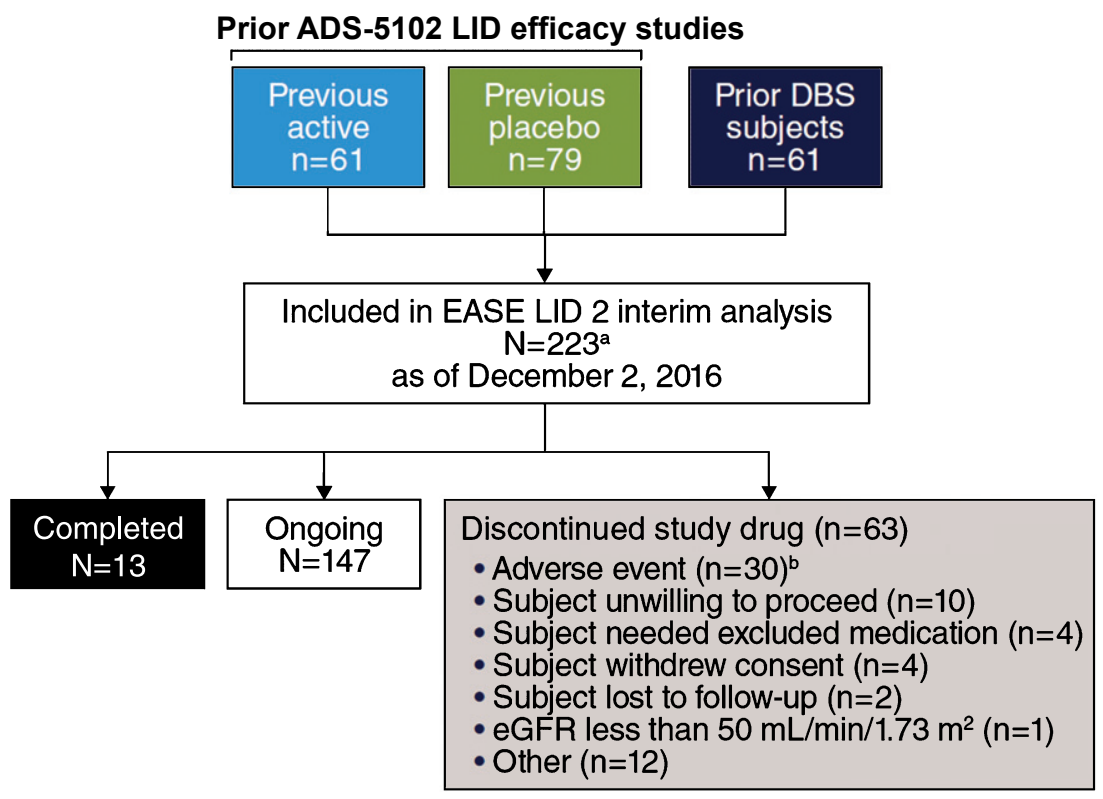

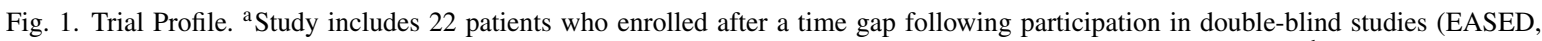
EASE LID, EASE LID 3) and were not summarized as a subgroup in subsequent analyses due to small sample size. ${ }^{\mathrm{b}}$ Case report form in interim data-cut for 2 additional patients reported study drug withdrawal as action taken in response to AE, while disposition record reported "other" and "ongoing." 
Table 2

Patient demographics and baseline characteristics (safety population)

\begin{tabular}{lcrrr}
\hline & Previous Active & Previous Placebo \\
Group $^{\mathrm{a}}(n=61)$ & Prior DBS Patients & $\begin{array}{c}\text { All } \\
\text { Group }^{\mathrm{a}}(n=79)\end{array}$ & Group $(n=61)$ & $\left(\mathrm{N}=223^{\mathrm{b}}\right)$ \\
\hline Age (years), mean (SD) & $64.2(9.93)$ & $65.8(8.80)$ & $60.2(9.20)$ & $63.7(9.31)$ \\
Age (years), $<65, \mathrm{n}(\%)$ & $28(45.9)$ & $31(39.2)$ & $39(63.9)$ & $109(48.9)$ \\
Age (years), $\geq 65, \mathrm{n}(\%)$ & $33(54.1)$ & $48(60.8)$ & $22(36.1)$ & $114(51.1)$ \\
Sex, Male, $\mathrm{n}(\%)$ & $34(55.7)$ & $45(57.0)$ & $41(67.2)$ & $131(58.7)$ \\
Race, White, $\mathrm{n}(\%)$ & $58(95.1)$ & $74(93.7)$ & $54(88.5)$ & $208(93.3)$ \\
BMI (kg/m $\left.{ }^{2}\right)$, mean (SD) & $25.8(6.0)$ & $25.7(4.8)$ & $27.3(4.9)$ & $26.1(5.2)$ \\
Years since PD diagnosis, mean (SD) & $11.2(4.5)$ & $10.0(4.1)$ & $14.7(6.3)$ & $11.8(5.3)$ \\
Duration of levodopa treatment (years), mean (SD) & $8.7(3.7)$ & $7.8(4.0)$ & $11.9(5.4)$ & $9.3(4.7)$ \\
Duration of levodopa-induced dyskinesia (years), mean (SD) & $4.6(3.4)$ & $4.0(2.5)$ & $8.0(4.4)$ & $5.3(3.7)$ \\
\hline
\end{tabular}

BMI, body mass index; DBS, deep-brain stimulation; PD, Parkinson's disease. ${ }^{\text {a }}$ These patients were previously enrolled in either EASE LID or EASE LID 3. ${ }^{b}$ Study includes 22 patients who enrolled after a time gap following participation in double-blind studies (EASED, EASE LID, EASE LID 3) and were not summarized as a subgroup in subsequent analyses due to small sample size.

Table 3

Overview of adverse events (AEs; safety population)

\begin{tabular}{lcccc}
\hline & $\begin{array}{c}\text { Previous Active } \\
\operatorname{Group}^{\mathrm{a}}(n=61)\end{array}$ & $\begin{array}{c}\text { Previous Placebo } \\
\text { Group }^{\mathrm{a}}(n=79)\end{array}$ & $\begin{array}{c}\text { Prior DBS Patients } \\
\text { Group }(n=61)\end{array}$ & $\begin{array}{c}\text { All } \\
\left(\mathrm{N}=223^{\mathrm{b}}\right)\end{array}$ \\
\hline No. $(\%)$ of patients with any & & & & \\
$\quad$ AE & $53(86.9)$ & $69(87.3)$ & $53(86.9)$ & $196(87.9)$ \\
Study drug-related AE & $29(47.5)$ & $41(51.9)$ & $25(41.0)$ & $110(49.3)$ \\
SAE & $11(18.0)$ & $13(16.5)$ & $9(14.8)$ & $38(17.0)$ \\
Study drug-related SAE & 0 & $1(1.3)$ & $1(1.6)$ & $2(0.9)$ \\
No. $(\%)$ of patients who permanently & & & & \\
discontinued treatment due to any & & $16(20.3)$ & $6(9.8)$ & $32(14.3)$ \\
$\quad$ AE & $5(8.2)$ & $12(15.2)$ & $5(8.2)$ & $22(9.9)$ \\
Study drug-related AE & $1(1.6)$ & & & \\
\hline
\end{tabular}

DBS, deep-brain stimulation; SAE, serious adverse event. ${ }^{\text {a }}$ These patients were previously enrolled in either EASE LID or EASE LID 3. ${ }^{\mathrm{b}}$ Study includes 22 patients who enrolled after a time gap following participation in double-blind studies (EASED, EASE LID, EASE LID 3) and were not summarized as a subgroup due to small sample size.

medications were used by $\leq 15 \%$ of patients per medication class. The doses of background PD medications were allowed to change, based on clinical judgment, during this long-term study. The mean levodopa dose for all patients at baseline was $758 \mathrm{mg}$ (SD 460) and $834 \mathrm{mg}$ (SD 535) at the time of the interim data cut-off date.

For the subset of patients with $\geq 1$ year of treatment $(n=122), 91 \%$ had either no change $(n=89)$, or an increase $(n=22)$, in their daily levodopa regimen at the 1-year time point (Supplemental Table 1). Additionally, for those subjects who entered the study taking a dopamine agonist $(n=75), 12 \%(n=9)$ had discontinued this medication at the 1-year time point.

\section{Adverse events}

An overview of AEs is provided in Table 3. The most common AEs ( $\geq 5 \%$ of patients) are reported in Table 4. Fall, visual hallucination, peripheral edema, and constipation were each reported by $\geq 10 \%$ of patients overall. Adverse events were the primary reason for study drug discontinuation in
32 patients (14.3\%). Thirty-eight patients (17.0\%) had a total of 52 SAEs; all but 2 were considered not related to study drug. The 2 drug-related SAEs were urinary tract infection $(n=1)$ and suicidal ideation $(n=1)$. Four deaths had occurred as of the data cut-off date; one death occurred on Day 55 (myocardial infarction), one occurred on Day 99 (pneumonia), one occurred on Day 190 (cardiac arrest), and another occurred on Day 425 (C. difficile sepsis, colonic pseudo-obstruction). No deaths were considered study-drug related.

Falls were the most commonly reported $\mathrm{AE}$ in the study at the time of the data cut-off date. A total of 56 patients $(25.1 \%)$ reported 1 or more falls. Among these advanced PD patients who experienced a fall, the majority were $\geq 65$ years of age and had other known risk factors for falls. For 45 of the 56 patients with a fall $\mathrm{AE}$, the event was considered not related to study drug.

Forty-five patients (20.2\%) reported hallucinations, which included visual hallucinations (43 patients [19.3\%]) and/or auditory hallucinations (5 patients [2.2\%]). Most of the patients (32 of 
Table 4

Most common adverse events ( $\geq 5 \%$ of all patients; safety population)

\begin{tabular}{lcccc}
\hline Preferred Term, $\mathrm{n}(\%)$ & $\begin{array}{c}\text { Previous Active } \\
\text { Group }^{\mathrm{a}}(n=61)\end{array}$ & $\begin{array}{c}\text { Previous Placebo } \\
\text { Group }^{\mathrm{a}}(n=79)\end{array}$ & $\begin{array}{c}\text { Prior DBS Patients } \\
\text { Group }(n=61)\end{array}$ & $\begin{array}{c}\text { All } \\
\left(\mathrm{N}=223^{\mathrm{b}}\right)\end{array}$ \\
\hline Fall & $12(19.7)$ & $20(25.3)$ & $16(26.2)$ & $56(25.1)$ \\
Visual hallucination & $10(16.4)$ & $20(25.3)$ & $9(14.8)$ & $43(19.3)$ \\
Peripheral edema & $9(14.8)$ & $9(11.4)$ & $9(14.8)$ & $29(13.0)$ \\
Constipation & $9(14.8)$ & $9(11.4)$ & $4(6.6)$ & $28(12.6)$ \\
Livedo reticularis & $6(9.8)$ & $4(5.1)$ & $5(8.2)$ & $18(8.1)$ \\
Nausea & $7(11.5)$ & $6(7.6)$ & $1(1.6)$ & $18(8.1)$ \\
Dry mouth & $3(4.9)$ & $6(7.6)$ & $3(4.9)$ & $16(7.2)$ \\
Insomnia & $6(9.8)$ & $3(3.8)$ & $4(6.6)$ & $16(7.2)$ \\
Dizziness & 0 & $8(10.1)$ & $3(4.9)$ & $15(6.7)$ \\
\hline
\end{tabular}

DBS, deep-brain stimulation. ${ }^{\mathrm{a}}$ These patients were previously enrolled in either EASE LID or EASE LID 3. ${ }^{\mathrm{b}}$ Study includes 22 patients who enrolled after a time gap following participation in double-blind studies (EASED, EASE LID, EASE LID 3) and were not summarized as a subgroup due to small sample size. Note: A patient was counted once within each preferred term. Percentages were calculated based on the number of patients in each group.

45 [71.1\%]) who experienced hallucinations were $\geq 65$ years of age. No other parameters examined (eGFR, weight, or sex) were determined to be predictive for risk of hallucinations. Intervention with an antipsychotic medication was required in 4 patients.

Regarding other AEs of clinical importance, livedo reticularis was reported by 18 patients $(8.1 \%)$. Four patients $(1.8 \%)$ reported impulse control disorders (ICD), but none of these patients withdrew from the study due to this AE. Two ICD events were considered mild, one moderate, and one severe. Study drug was interrupted because of ICD in 1 patient. None of the patients who reported an ICD had a change in eGFR of $>20 \%$ measured around the time of the events. One patient from the previous placebo group attempted suicide and another patient from the prior DBS patients group reported suicidal ideation with intent for self-harm. Both of these patients had a history of anxiety and depression and subsequently withdrew from the study. Orthostatic hypotension or hypotension was reported for 7 patients (3.1\%).

Patients who received continuous treatment with ADS-5102 (direct enrolment from EASE LID or EASE LID 3 active arms) experienced fewer AEs compared with patients who received placebo in previous trials and received ADS-5102 for the first time in this open-label study (Table 3).

The most common AEs leading to discontinuation (reported by $\geq 2$ patients) were falls $(2.2 \%, n=5)$, visual hallucinations $(2.2 \%, n=5)$, and peripheral edema $(0.9 \%, n=2)$. Figure 2 characterizes discontinuation rates due to any $\mathrm{AE}$ for patients enrolling into the open-label study directly from EASE LID (Fig. 2A) and EASE LID 3 (Fig. 2B) for both previous placebo and previous active groups. Incidence of discontinuation of ADS-5102 during open-label dosing was lower in patients who continued ADS-5102 dosing from the prior controlled trials compared with those who initiated treatment of ADS-5102 in EASE LID 2.

AEs exhibited by $\geq 5 \%$ of patients in any subgroup were characterized by age group $(\geq 65$ years vs $<65$ years). AEs were reported for $91.2 \%$ of patients $\geq 65$ years of age and $84.4 \%$ of patients $<65$ years of age. Several AEs were reported with greater frequency in patients aged $\geq 65$ years compared with patients $<65$ years, such as falls $(33.3 \%$ vs $16.5 \%)$, visual hallucinations (27.2\% vs $11.0 \%)$, and peripheral edema ( $19.3 \%$ vs $6.4 \%$ ). Conversely, dry mouth was reported in $5.3 \%$ of patients $\geq 65$ years of age compared with $9.2 \%$ of patients $<65$ years of age.

In general, vital signs and laboratory results remained consistent with baseline values and similar across all groups.

\section{MDS-UPDRS}

At the start of the open-label study, MDS-UPDRS, Part IV (motor complications) scores for patients enrolling directly from EASE LID (Fig. 3A) and EASE LID 3 (Fig. 3B) studies were lower at baseline in patients previously randomized to ADS-5102 compared with patients previously randomized to placebo and were maintained up to Week 64. For both groups not receiving ADS-5102 at baseline (previous placebo group and prior DBS patients group), mean scores decreased from baseline to week 8 (first post-baseline assessment) and remained stable through week 64 (Table 5). A similar effect was seen within the following subparts, Part IV, item 4.1 scores (time with dyskinesia), Part IV, item 4.2 (functional impact of dyskinesia), and notably for Part IV, item 

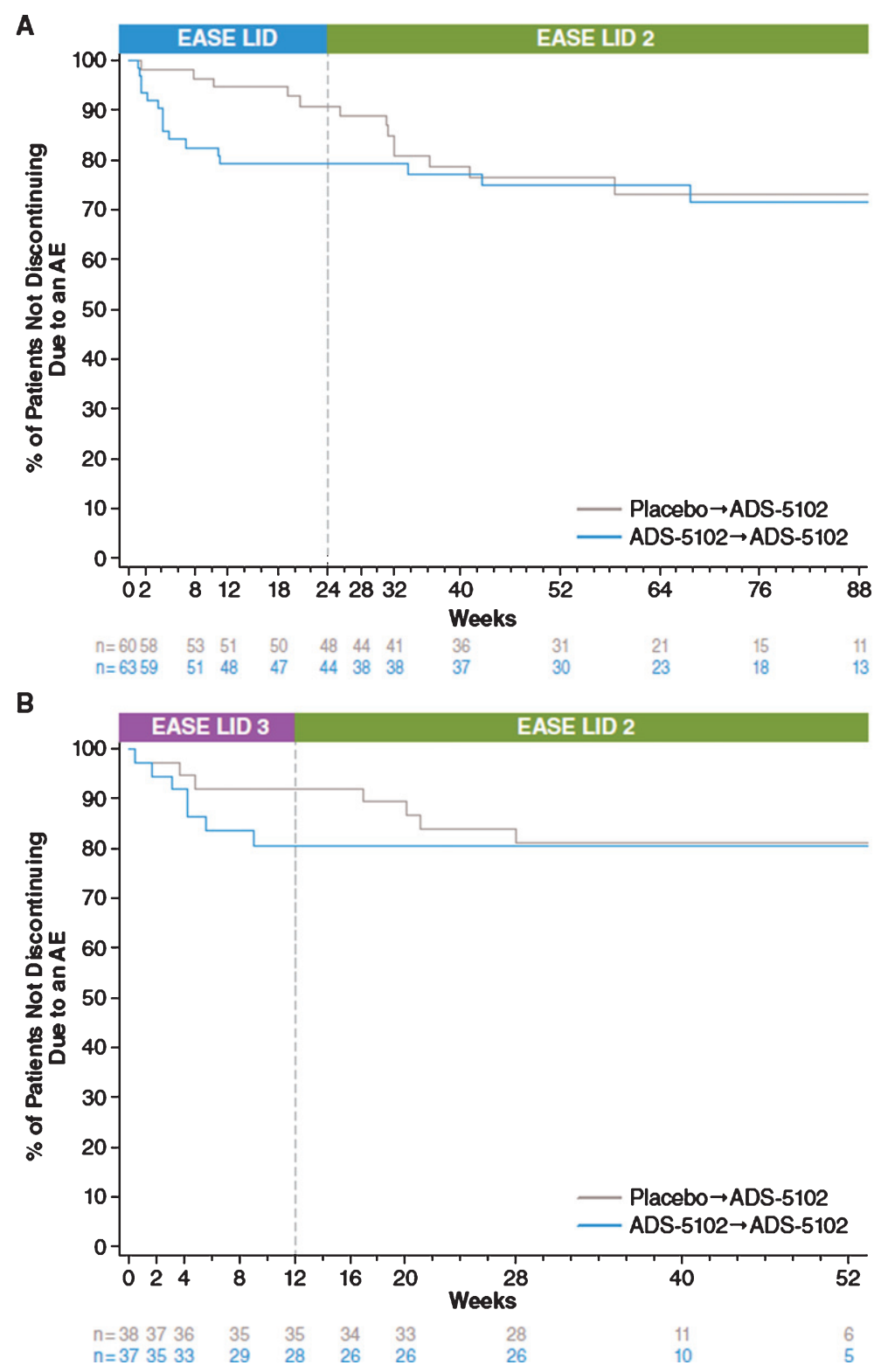

Fig. 2. Kaplan-Meier curves for Discontinuation Due to Adverse Event.

4.4 scores (functional impact of motor fluctuations [OFF]). Table 6 summarizes change from baseline in the MDS-UPDRS, Combined Score (Parts I-III). Mean scores showed relatively small changes from baseline at each measured time point across all groups (Fig. 4).

\section{DISCUSSION}

Open-label interim safety data from 223 patients treated with $274 \mathrm{mg}$ ADS-5102 for up to
64 weeks show long-term safety and tolerability of ADS-5102, consistent with the randomized controlled clinical trials. Falls were the most common AEs: however, a majority were not related to study drug and likely reflected longterm follow-up of an advanced PD population [19]. The other common AEs with ADS-5102 treatment are largely predicted by its NMDAreceptor-antagonist activity (e.g., hallucinations) and anticholinergic activity (e.g., dry mouth, constipation, nausea). 

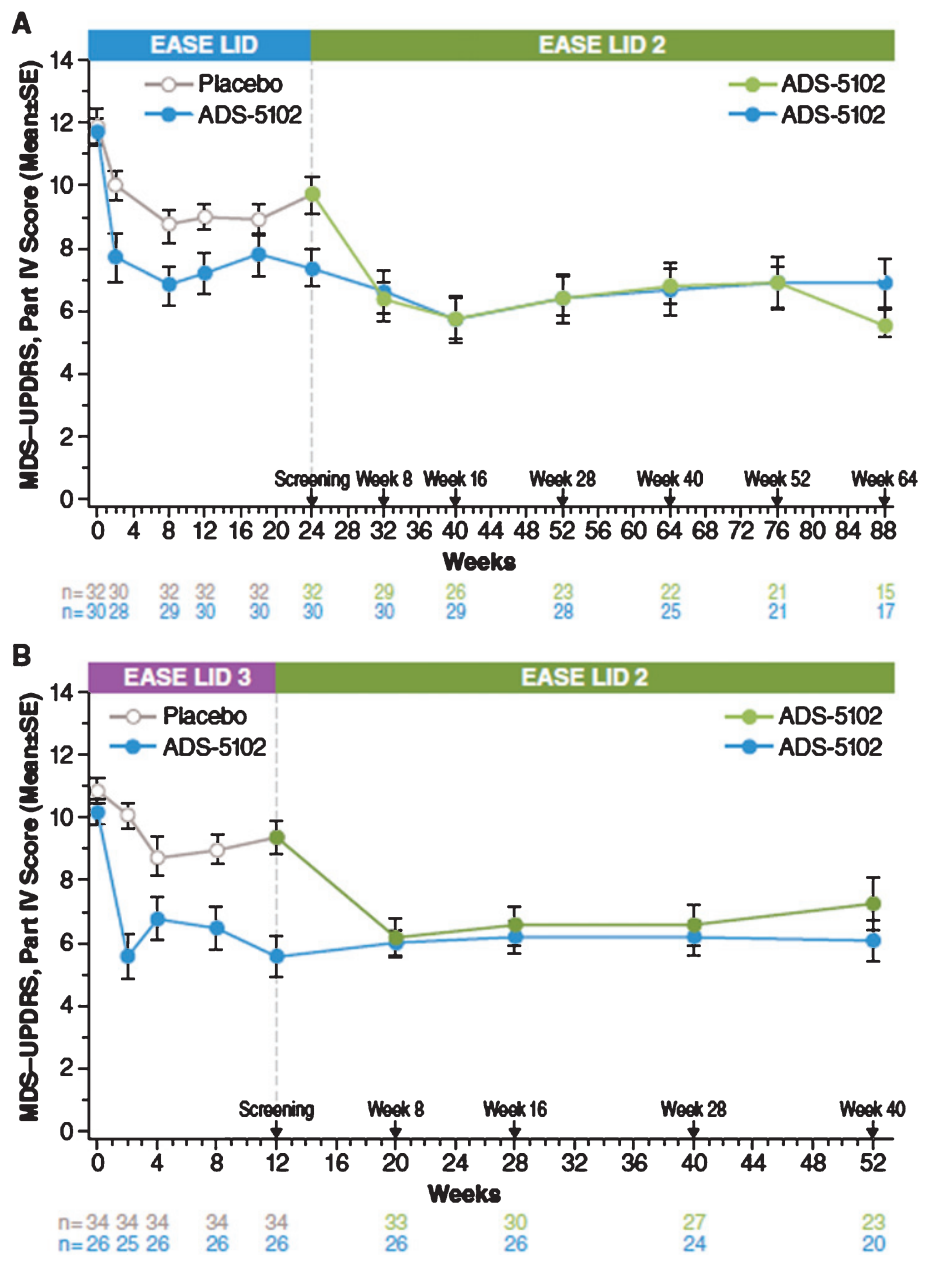

Fig. 3. MDS-UPDRS Part IV - Double-blind/Open-Label Study Experience. MDS-UPDRS, Movement Disorder Society-Unified Parkinson's Disease Rating Scale.

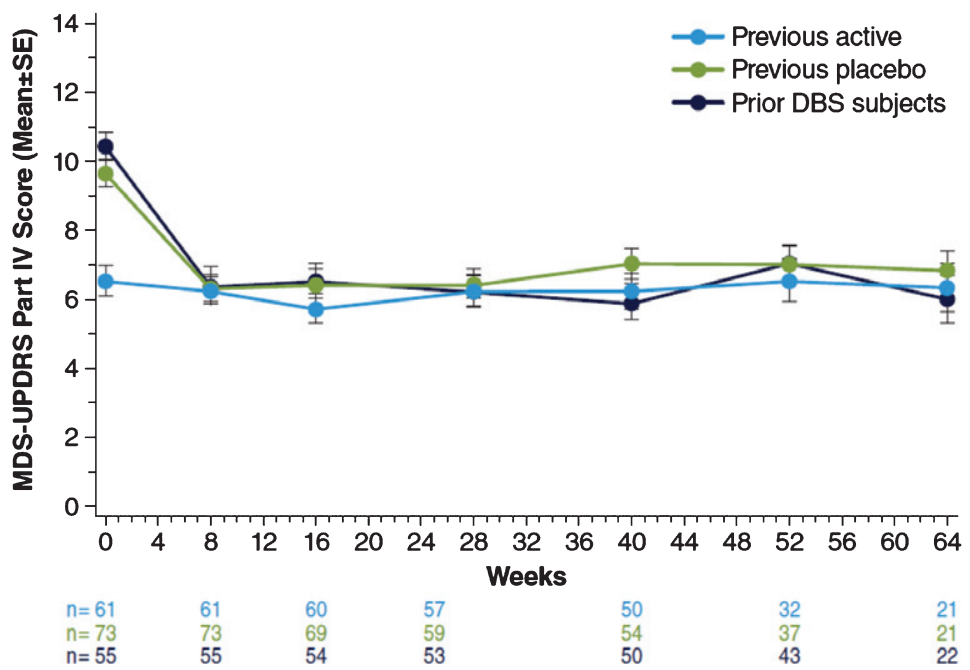

Fig. 4. MDS-UPDRS Part IV Scores. MDS-UPDRS, Movement Disorder Society-Unified Parkinson's Disease Rating Scale. 
Table 5

Change from baseline in MDS-UPDRS, Part IV and subscores (efficacy population)

\begin{tabular}{|c|c|c|c|c|}
\hline & \multicolumn{4}{|c|}{ Mean change from baseline (SD), $\mathrm{n}$} \\
\hline & $\begin{array}{l}\text { Previous Active } \\
\text { Group }^{\mathrm{a}}(n=61)\end{array}$ & $\begin{array}{c}\text { Previous Placebo } \\
\text { Group }^{\text {a }}(n=78) \\
\end{array}$ & $\begin{array}{c}\text { Prior DBS Patients } \\
\text { Group }(n=60) \\
\end{array}$ & $\begin{array}{c}\text { All } \\
\left(\mathrm{N}=221^{\mathrm{b}}\right)\end{array}$ \\
\hline MDS-UPDR & t IV (motor compl & ns) & & \\
\hline $\begin{array}{l}\text { Baseline } \\
8 \text { weeks } \\
16 \text { weeks } \\
28 \text { weeks } \\
40 \text { weeks } \\
52 \text { weeks } \\
64 \text { weeks }\end{array}$ & $\begin{aligned} 6.5(3.4) n & =61 \\
-0.3(3.2) n & =61 \\
-0.8(3.6) & =60 \\
-0.3(3.6) n & =57 \\
0.2(4.0) n & =50 \\
0.5(4.1) n & =32 \\
-0.3(3.8) n & =21\end{aligned}$ & $\begin{array}{r}9.6(3.1) n=73 \\
-3.4(3.3) n=73 \\
-3.2(3.6) n=69 \\
-3.3(3.1) n=59 \\
-2.7(3.4) n=54 \\
-2.7(3.8) n=37 \\
-2.3(3.6) n=21\end{array}$ & $\begin{array}{l}10.4(2.8) n=55 \\
-4.0(4.2) n=55 \\
-3.9(3.7) n=54 \\
-4.4(3.8) n=53 \\
-4.7(4.1) n=50 \\
-3.3(3.6) n=43 \\
-4.5(3.5) n=22\end{array}$ & $\begin{aligned} 8.9(3.5) \quad n & =203 \\
-2.6(3.9) & n=203 \\
-2.5(4.0) & n=196 \\
-2.5(3.9) & n=181 \\
-2.5(4.3) n & =166 \\
-2.1(4.1) & n=118 \\
-2.6(4.0) \quad n & =70\end{aligned}$ \\
\hline $\begin{array}{l}\text { MDS-UPDR } \\
\text { Baseline } \\
8 \text { weeks } \\
16 \text { weeks } \\
28 \text { weeks } \\
40 \text { weeks } \\
52 \text { weeks } \\
64 \text { weeks }\end{array}$ & $\begin{aligned} \text { rt IV, item } 4.1 \text { (tim } \\
1.6(1.1) n=61 \\
-0.3(1.0) n=61 \\
-0.4(1.0) n=60 \\
-0.4(1.0) n=57 \\
-0.2(1.2) n=50 \\
-0.2(1.1) n=32 \\
-0.3(1.2) n=21\end{aligned}$ & $\begin{array}{r}1.9(1.0) n=73 \\
-0.7(0.9) n=73 \\
-0.8(1.2) n=69 \\
-1.0(1.0) n=59 \\
-0.9(1.0) n=54 \\
-0.9(1.1) n=37 \\
-0.8(1.2) n=22\end{array}$ & $\begin{aligned} 1.8(0.8) n & =55 \\
-0.8(1.1) n & =55 \\
-1.0(0.9) n & =54 \\
-0.9(1.0) n & =53 \\
-0.9(1.1) n & =50 \\
-0.8(1.0) n & =43 \\
-1.0(1.1) n & =22\end{aligned}$ & $\begin{aligned} 1.8(1.0) & n=203 \\
-0.6(1.0) & n=203 \\
-0.7(1.0) & n=196 \\
-0.8(1.0) & n=181 \\
-0.7(1.1) \quad n & =166 \\
-0.7(1.2) \quad n & =118 \\
-0.7(1.2) n & =71\end{aligned}$ \\
\hline $\begin{array}{l}\text { MDS-UPDR } \\
\text { Baseline } \\
8 \text { weeks } \\
16 \text { weeks } \\
28 \text { weeks } \\
40 \text { weeks } \\
52 \text { weeks } \\
64 \text { weeks }\end{array}$ & $\begin{aligned} \text { rt IV, item } 4.2 \text { (fun } \\
0.9(1.0) n=61 \\
-0.1(0.9) n=61 \\
-0.2(0.7) n=60 \\
-0.1(0.9) n=57 \\
0.3(1.2) n=50 \\
0.4(1.2) n=32 \\
0.1(1.1) n=21\end{aligned}$ & $\begin{array}{r}1.9(0.9) n=73 \\
-0.9(1.1) n=73 \\
-1.0(1.1) n=69 \\
-1.1(1.1) n=59 \\
-1.1(1.0) n=54 \\
-0.9(1.0) n=37 \\
-1.2(1.0) n=22\end{array}$ & $\begin{aligned} 2.4(1.0) n & =55 \\
-1.5(1.4) n & =55 \\
-1.4(1.2) n & =54 \\
-1.6(1.2) n & =53 \\
-1.4(1.2) n & =50 \\
-1.4(1.1) n & =43 \\
-1.3(1.0) n & =22\end{aligned}$ & 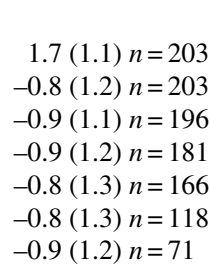 \\
\hline $\begin{array}{l}\text { MDS-UPDR } \\
\text { Baseline } \\
8 \text { weeks } \\
16 \text { weeks } \\
28 \text { weeks } \\
40 \text { weeks } \\
52 \text { weeks } \\
64 \text { weeks }\end{array}$ & $\begin{array}{c}\text { IV, item } 4.3 \text { (tim } \\
0.9(0.6) n=61 \\
0.1(0.6) n=61 \\
0.1(0.7) n=60 \\
0.0(0.7) n=57 \\
0.0(0.7) n=50 \\
0.1(0.7) n=32 \\
0.0(0.8) n=21\end{array}$ & $\begin{aligned} & \text { in the OFF state) } \\
1.4(0.6) n & =73 \\
-0.3(0.8) n & =73 \\
-0.3(0.7) n & =69 \\
-0.4(0.7) n & =59 \\
-0.3(0.6) n & =54 \\
-0.4(0.8) n & =37 \\
-0.3(0.8) n & =22\end{aligned}$ & $\begin{aligned} 1.3(0.6) n & =55 \\
-0.4(0.6) n & =55 \\
-0.3(0.8) n & =54 \\
-0.4(0.8) n & =53 \\
-0.4(0.9) n & =50 \\
-0.2(0.6) n & =43 \\
-0.5(0.7) n & =22\end{aligned}$ & $\begin{aligned} 1.2(0.6) & n=203 \\
-0.2(0.7) & n=203 \\
-0.2(0.8) & n=196 \\
-0.2(0.8) & n=181 \\
-0.2(0.8) n & =166 \\
-0.2(0.7) n & =118 \\
-0.2(0.8) & n=71\end{aligned}$ \\
\hline $\begin{array}{l}\text { MDS-UPDR } \\
\text { Baseline } \\
8 \text { weeks } \\
16 \text { weeks } \\
28 \text { weeks } \\
40 \text { weeks } \\
52 \text { weeks } \\
64 \text { weeks }\end{array}$ & $\begin{array}{r}\text { IV, item } 4.4 \text { (fun } \\
1.4(1.2) n=61 \\
0.0(1.2) n=61 \\
-0.1(1.5) n=60 \\
-0.1(1.3) n=57 \\
0.1(1.4) n=50 \\
0.1(1.4) n=32 \\
-0.5(1.4) n=21\end{array}$ & $\begin{array}{r}\text { impact of fluctua } \\
2.0(1.3) n=73 \\
-0.6(1.4) n=73 \\
-0.6(1.3) n=69 \\
-0.4(1.3) n=59 \\
-0.1(1.4) n=54 \\
-0.4(1.2) n=37 \\
-0.3(1.4) n=22\end{array}$ & $\begin{aligned} 2.3(1.1) n & =55 \\
-0.9(1.4) n & =55 \\
-0.9(1.1) n & =54 \\
-1.0(1.2) n & =53 \\
-1.1(1.2) n & =50 \\
-0.7(1.1) n & =43 \\
-1.2(1.3) n & =22\end{aligned}$ & $\begin{aligned} 1.9(1.3) & n=203 \\
-0.5(1.4) & n=203 \\
-0.5(1.4) n & =196 \\
-0.5(1.3) & n=181 \\
-0.4(1.5) n & =166 \\
-0.4(1.3) n & =118 \\
-0.7(1.4) n & =71\end{aligned}$ \\
\hline
\end{tabular}

DBS, brain stimulation; MDS-UPDRS, Movement Disorder Society-Unified Parkinson's Disease Rating Scale. ${ }^{a}$ These patients were previously enrolled in either EASE LID or EASE LID 3. ${ }^{b}$ Study includes 22 patients who enrolled after a time gap following participation in double-blind studies (EASED, EASE LID, EASE LID 3) and were not summarized as a subgroup due to small sample size. Note: No meaningful changes were observed in MDS-UPDRS Part IV Items 4.5 or 4.6.

Neuropsychiatric AEs, notably hallucinations, are the most commonly observed clinically relevant AEs with ADS-5102 treatment. These events were mostly mild to moderate, and usually did not require intervention or lead to study drug discontinuation. Two patients treated with ADS-5102 experienced suicidal ideation and/or suicide attempt, neither of which was fatal, and study drug was discontinued. It should be noted that suicidal ideation and death ideation are common in the PD population, although suicide attempts may be rare [20]. During treatment, patients should be monitored for depressed mood, depression, changes in behavior or thinking that are not typical for the patient, or suicidal ideation or behavior.

Visual hallucinations, falls, and peripheral edema occurred more frequently in patients aged $\geq 65$ years compared with those $<65$ years. In addition to older age, PD may be an independent risk factor for visual 
Table 6

Change from baseline in MDS-UPDRS, Combined Score (Parts I-III) (efficacy population)

\begin{tabular}{lcrrr}
\hline MDS-UPDRS Combined Scores & \multicolumn{2}{c}{ Mean (SD), $\mathrm{n}$} \\
\cline { 2 - 6 } & $\begin{array}{c}\text { Previous Active } \\
\operatorname{Group}^{\mathrm{a}}(n=61)\end{array}$ & $\begin{array}{c}\text { Previous Placebo } \\
\operatorname{Group}^{\mathrm{a}}(n=78)\end{array}$ & $\begin{array}{c}\text { Prior DBS Patients } \\
\text { Group }(n=60)\end{array}$ & $\begin{array}{c}\text { All } \\
\left(\mathrm{N}=221^{\mathrm{b}}\right)\end{array}$ \\
\hline Baseline & $41.9(18.3) n=61$ & $45.8(19.2) n=73$ & $52.4(16.6) n=55$ & $46.9(19.0) n=203$ \\
Change from baseline at Week 8 & $1.1(10.0) n=61$ & $-2.8(14.0) n=73$ & $-5.3(10.7) n=55$ & $-2.1(12.2) n=203$ \\
Change from baseline at Week 16 & $1.6(13.3) n=60$ & $-1.3(16.1) n=69$ & $-5.2(11.3) n=54$ & $-1.0(14.4) n=196$ \\
Change from baseline at Week 28 & $4.8(10.0) n=57$ & $1.6(12.4) n=59$ & $-5.3(13.0) n=53$ & $0.8(12.7) n=180$ \\
Change from baseline at Week 40 & $7.8(15.4) n=50$ & $-0.5(15.6) n=54$ & $-4.8(12.5) n=50$ & $0.8(15.7) n=166$ \\
Change from baseline at Week 52 & $15.5(15.8) n=31$ & $2.2(17.0) n=37$ & $-4.3(16.7) n=43$ & $3.2(18.1) n=117$ \\
Change from baseline at Week 64 & $11.3(16.8) n=21$ & $4.7(15.3) n=22$ & $-6.5(10.5) n=22$ & $2.8(15.9) n=71$ \\
\hline
\end{tabular}

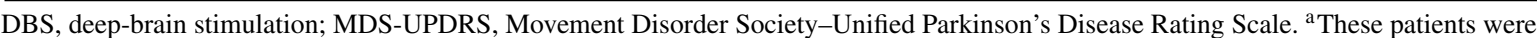
previously enrolled in either EASE LID or EASE LID 3. ${ }^{b}$ Study includes 22 patients who enrolled after a time gap following participation in double-blind studies (EASED, EASE LID, EASE LID 3) and were not summarized as a subgroup due to small sample size.

hallucinations and other symptoms of psychosis, possibly related to altered neurotransmitter functioning associated with the disease [21]. Although the incidence of AEs was lower in those patients who received ADS-5102 prior to enrolling in the openlabel study, those who had experienced AEs in the double-blind phase may have been less likely to enroll in the open-label follow-up study. Nonetheless, an initially favorable safety profile appeared to be maintained in the following months on openlabel treatment. ADS-5102 was also well tolerated by patients with prior DBS.

In addition, results of this interim analysis showed that for patients with longer term treatment with ADS-5102, entering from the EASE LID or EASE LID 3 studies, ADS-5102 treatment maintained antidyskinetic and secondary OFF effects. Reduction in MDS-UPDRS, Part IV score was primarily due to reduction in items 4.2 (functional impact of LID) and 4.4 (functional impact of OFF). Antidyskinetic effects were achieved without compromising underlying control of PD symptoms, as demonstrated by the absence of change in combined score for MDS-UPDRS Parts I, II, and III.

As patients with PD have increasing dyskinesia with increased disease duration, levodopa duration, and increasing levodopa dose, LID can become increasingly disabling over time [22]. No medications are currently approved for the treatment of LID, which represents a significant unmet medical need in patients with PD. Two placebo-controlled phase 3 studies have provided robust evidence that ADS-5102 reduces LID by the primary outcome measure (reduction in Unified Dyskinesia Rating Scale total score) and across multiple secondary outcome measures (PD home diaries, MDS-UPDRS, and Clinician's Global Impression of Change) that assessed several aspects of dyskinesia (time, severity, and impact).
These studies also demonstrated a reduction in OFF time, and to our knowledge, ADS-5102 is the only oral pharmacologic agent demonstrating efficacy for both OFF time and LID.

Analyses of safety data from the controlled studies and this ongoing long-term, open-label safety study of ADS-5102 in patients with PD and LID have demonstrated that ADS-5102 has a manageable safety profile. Interpretation of these results should take into account that ADS-5102 and amantadine IR tablets have different pharmacokinetic profiles, and milligram-per-milligram dosages are not interchangeable. Overall, these results suggest that ADS-5102 has potential for safe and effective long-term treatment of LID in patients with PD.

\section{ACKNOWLEDGMENTS}

We acknowledge and thank the study participants; the EASE LID 2 Study Investigators, including the Steering Committee and their staff; and Charles Davis, PhD, CSD Biostatistics, who provided statistical and analysis support. Under the direction of the authors, editorial assistance was provided by Cory Hussar, PhD, of The Curry Rockefeller Group, LLC, which was funded by Adamas Pharmaceuticals, Inc.

\section{CONFLICT OF INTEREST}

RAH is supported in part by a center grant from the National Parkinson's Disease Foundation. He received payment from Adamas for participating as a Steering Committee member and reports consulting fees from Teva Pharmaceuticals, USB Biosciences, AbbVie, Novartis, Biotie Therapies, Lundbeck, Pfizer, Allergan Neuroscience, Neurocrine Biosciences, Chelsea Therapeutics, Auspex, 
Acadia Pharmaceuticals, Michael J. Fox Foundation, GLG, AstraZeneca, Acorda Therapeutics, Impax Pharmaceuticals, Cynapsus Therapeutics, USWorldMeds, Neurospore, and Prexton; salary support grants from National Parkinson Foundation; and salary from University of South Florida.

$\mathrm{RP}$ is receiving or has received honoraria or payments for consulting from AbbVie, Acadia, Acorda, Adamas, Cynapsus, Global Kinetics, Impax, Lundbeck, Medtronic, Neurocrine, Sage, St Jude Medical, Teva Neuroscience, Medtronic, UCB, and US WorldMeds. He has received research grants from Acadia, Acorda, Adamas, Avid, Biotie, Boston Scientific, Civitas, Cynapsus, Kyowa, NIH/NINDS, NPF, Pfizer, and PSG/University of Rochester. He has also served on the data monitoring committee for Ceregene and Ionis. $\mathrm{He}$ has received personal compensation as the Co-Editor-in-Chief of the International Journal of Neuroscience.

CMT is an employee of the University of California-San Francisco and the San Francisco Veterans Affairs Medical Center. She serves on the Scientific Advisory Boards of the Michael J. Fox Foundation and the National Spasmodic Dysphonia Association as a voluntary consultant and has provided paid consulting services to Ultragenyx Pharmaceuticals, Neurocrine Biosciences, Cynapsus Therapeutics, Sage Biometrics, and Adamas Pharmaceuticals. She has received compensation for serving on Data Monitoring Committees from Biotie Therapies, Voyager Therapeutics, and Intec Pharma. She receives grant support from the Michael J. Fox Foundation, the Parkinson's Disease Foundation, the Department of Defense, and the National Institutes of Health.

WO has served as a consultant for Mundipharma, Novartis, and UCB Pharma; on advisory boards for Boehringer Ingelheim, Merck, Sharp \& Dohme, Medtronic, Mundipharma, Neuropore, Novartis, UCB Pharma, and Teva; and received honoraria for presenting lectures from AbbVie, Desitin, Boehringer Ingelheim, Mundipharma, Novartis, Orion Pharma, Schwarz Pharma Neuroscience/UCB, and Teva. He has received scientific grants from the German Ministry of Education and Health, the German Research Foundation, the Charitable Hertie Foundation, the Internal Parkinson Fonds, the Michael J. Fox Foundation, and Novartis Pharma Germany, and holds shares in Merck, Medigene, and Roche.

SHI has received honoraria for CME, consultant, research grants, and/or promotional speaker on behalf of AbbVie, Acadia, Acorda, Adamas, Addex, Allergan, Amarantus, Auspex, Avid, Axovant, AZ Therapies, Biogen, Biotie, Britannia, Cynapsus, Eisai, Eli Lilly, GE Healthcare, Impax, Intec Pharma, Ipsen, Kyowa, Lundbeck, Medtronics, Merz, Michael J. Fox Foundation, Neurocrine, Neuroderm, NINDS/NIH, Parkinson Study Group, Pfizer, Pharma2B, Prothena, Roche, Sanofi, Shire, Sunovion, Teva, UCB, US World Meds, and XenoPort.

$\mathrm{RJ}$ is an employee of and has received compensation and stock options from Adamas.

LF is an employee of and has received compensation and stock options from Adamas.

MJS is a consultant to and has received compensation and stock options from Adamas. She has also received consultancy payments from Cymabay Therapeutics, Inc., and Adheron Therapeutics.

\section{SUPPLEMENTARY MATERIAL}

The supplementary material is available in the electronic version of this article: http://dx.doi. org/10.3233/JPD-171134.

\section{REFERENCES}

[1] Connolly BS, \& Lang AE (2014) Pharmacological treatment of Parkinson disease: A review. JAMA, 311, 1670-1683.

[2] Lindholm D, Makela J, Di Liberto V, Mudo G, Belluardo N, Eriksson O, \& Saarma M (2016) Current disease modifying approaches to treat Parkinson's disease. Cell Mol Life Sci, 73, 1365-1379.

[3] Hornykiewicz O (2010) A brief history of levodopa. J Neurol, 257, S249-S252.

[4] Olanow CW, Stern MB, \& Sethi K (2009) The scientific and clinical basis for the treatment of Parkinson disease (2009). Neurology, 72, S1-S136.

[5] Daneault JF, Carignan B, Sadikot AF, Panisset M, \& Duval C (2013) Drug-induced dyskinesia in Parkinson's disease. Should success in clinical management be a function of improvement of motor repertoire rather than amplitude of dyskinesia? BMC Med, 11, 76.

[6] Ahlskog JE, \& Muenter MD (2001) Frequency of levodopa-related dyskinesias and motor fluctuations as estimated from the cumulative literature. Mov Disord, 16, 448-458.

[7] Rascol O, Perez-Lloret S, Damier P, Delval A, Derkinderen P, Destee A, Meissner WG, Tison F, \& Negre-Pages L (2015) Falls in ambulatory non-demented patients with Parkinson's disease. J Neural Transm (Vienna), 122, 1447-1455.

[8] Suh DC, Pahwa R, \& Mallya U (2012) Treatment patterns and associated costs with Parkinson's disease levodopa induced dyskinesia. J Neurol Sci, 319, 24-31.

[9] Chapuis S, Ouchchane L, Metz O, Gerbaud L, \& Durif F (2005) Impact of the motor complications of Parkinson's disease on the quality of life. Mov Disord, 20, 224-230. 
[10] Hechtner MC, Vogt T, Zollner Y, Schroder S, Sauer JB, Binder H, Singer S, \& Mikolajczyk R (2014) Quality of life in Parkinson's disease patients with motor fluctuations and dyskinesias in five European countries. Parkinsonism Relat Disord, 20, 969-974.

[11] Fox SH, Katzenschlager R, Lim SY, Ravina B, Seppi K, Coelho M, Poewe W, Rascol O, Goetz CG, \& Sampaio C (2011) The Movement Disorder Society evidence-based medicine review update: Treatments for the motor symptoms of Parkinson's disease. Mov Disord, 26(Suppl 3), S2-S41.

[12] Pahwa R, Factor SA, Lyons KE, Ondo WG, Gronseth G, Bronte-Stewart H, Hallett M, Miyasaki J, Stevens J, Weiner WJ, \& Quality Standards Subcommittee of the American Academy of Neurology (2006) Practice Parameter: Treatment of Parkinson disease with motor fluctuations and dyskinesia (an evidence-based review): Report of the Quality Standards Subcommittee of the American Academy of Neurology. Neurology, 66, 983-995.

[13] Verhagen Metman L, Del Dotto P, van den Munckhof P, Fang J, Mouradian MM, \& Chase TN (1998) Amantadine as treatment for dyskinesias and motor fluctuations in Parkinson's disease. Neurology, 50, 1323-1326.

[14] Parkes JD, Zilkha KJ, Marsden P, Baxter RC, \& Knill-Jones RP (1970) Amantadine dosage in treatment of Parkinson's disease. Lancet, 1, 1130-1133.

[15] Pahwa R, Tanner CM, Hauser RA, Isaacson SH, Nausieda PA, Truong DD, Agarwal P, Hull KL, Lyons KE, Johnson R, \& Stempien MJ (2017) ADS-5102 (Amantadine) extended-release capsules for levodopa-induced dyskinesia in Parkinson Disease (EASE LID Study): A randomized clinical trial. JAMA Neurol, doi: 10.1001/jamaneurol.2017.0943 [Epub ahead of print].
[16] Pahwa R, Tanner CM, Hauser RA, Sethi K, Isaacson S, Truong D, Struck L, Ruby AE, McClure NL, Went GT, \& Stempien MJ (2015) Amantadine extended release for levodopa-induced dyskinesia in Parkinson's disease (EASED Study). Mov Disord, 30, 788-795.

[17] Oertel W, Eggert K, Pahwa R, Tanner CM, Hauser RA, Trenkwalder C, Ehret R, Azulay JP, Isaacson S, Felt L, \& Stempien MJ (2017) ADS-5102 for the treatment of levodopa-induced dyskinesia in Parkinson's disease (EASE LID 3 study). Mov Disord, in press.

[18] Hauser RA, Pahwa R, Tanner CM, Oertel W, Johnson R, Felt L, \& Stempien MJ (2017) Update to Interim Results of a Long-term Open-label Safety Study of ADS-5102 (amantadine hydrochloride) Extended-Release Capsules for Treatment of Levodopa-Induced Dyskinesia (LID) (EASE LID 2 Study). Poster presented at: 1st Pan American Parkinson's Disease and Movement Disorders Congress; February 24-26, 2017, Miami, FL. Poster 92.

[19] Hiorth YH, Larsen JP, Lode K, \& Pedersen KF (2014) Natural history of falls in a population-based cohort of patients with Parkinson's disease: An 8-year prospective study. Parkinsonism Relat Disord, 20, 1059-1064.

[20] Nazem S, Siderowf AD, Duda JE, Brown GK, Ten Have T, Stern MB, \& Weintraub D (2008) Suicidal and death ideation in Parkinson's disease. Mov Disord, 23, 1573-1579.

[21] Chang A, \& Fox SH (2016) Psychosis in Parkinson's disease: Epidemiology, pathophysiology, and management. Drugs, 76, 1093-1118.

[22] Thanvi B, Lo N, \& Robinson T (2007) Levodopa-induced dyskinesia in Parkinson's disease: Clinical features, pathogenesis, prevention and treatment. Postgrad Med J, 83, 384-388. 